\title{
Effect of increasing heart rate on Doppler indices of left ventricular performance in healthy men
}

\author{
T Oniki, Y Hashimoto, S Shimizu, T Kakuta, M Yajima, F Numano
}

\begin{abstract}
Objective-To investigate the effects of heart rate on the Doppler measurements of left ventricular function and to determine the normal pattern of rate dependency.

Setting-University hospital specialising in internal medicine.

Participants-14 healthy male volunteers 10 of whom were studied.

Intervention: Transoesophageal atrial pacing.

Main outcome measures-At paced rates of 70,80 , and $90 \mathrm{ppm}$ the ratio of early to late peak transmitral flow velocity (E/A) was 1.97 (0.28), 1.49 (0.21), and $0.95(0.11)$ respectively; the ratio of early to late time-velocity integrals of transmitral flow (Ei/Ai) was 3.03 (0.51), $2 \cdot 11(0 \cdot 24)$, and $1 \cdot 14(0 \cdot 30)$ respectively; and the atrial filling fraction (AFF) was $0.17(0.03), 0.21,(0.04)$, and $0.24(0.04)$ (mean (SD)).
\end{abstract}

Results-Heart rate showed a linear correlation with E/A $\left(r^{2}=0.806\right), \mathrm{Ei} / \mathrm{Ai}$ $\left(r^{2}=0.838\right)$, and AFF $\left(r^{2}=0.343\right)$. Neither the peak aortic flow velocity or the mean aortic flow acceleration showed significant changes during pacing at rates of $70,80,90$, and $100 \mathrm{ppm}$.

Conclusions-E/A and Ei/Ai can be expected to decrease by 0.5 and 0.9 for each increase of 10 beats/min in heart rate.

Knowledge of this relation may be useful for the development of algorithms to correct for heart rate when diastolic function is assessed.

Third Department of Internal Medicine, Tokyo Medical and Dental University, School of Medicine, Tokyo, Japan T Oniki

Y Hashimoto

S Shimizu

T Kakuta

M Yajima

F Numano

Correspondence to

T Oniki, Third Department of Internal Medicine, Tokyo Medical and Dental University, School of Medicine, 1-5-45 Yushima, Bunkyo-ku, Tokyo 113, Japan.

Accepted for publication 4 March 1992
(Br Heart J 1992;68:425-9)

Doppler echocardiography is a useful noninvasive procedure for evaluating left ventricular systolic ${ }^{12}$ and diastolic ${ }^{34}$ functions. Physiological variables, including the heart rate, affect cardiac performance and Doppler measurements. ${ }^{56}$ However, the normal pattern of heart rate dependency of those measurements is still unclear. Clarification of the relation between the heart rate and left ventricular performance in healthy individuals would allow the application of echocardiography to be refined. We studied the influence of altera- tions in heart rate on Doppler indices of left ventricular performance.

Subjects and methods STUDY POPULATION

We recruited 14 healthy male volunteers; four were excluded because of intolerable discomfort caused by pacing, unsatisfactory Doppler recordings, or a high sinus rate. The remaining 10 men (aged 25-30 (27.2 (1.7)) were free of illness as determined by their history and physical examination as well as by 12 lead electrocardiogram and echocardiogram. We obtained informed consent before the study. The men were fasting, non-sedated, and were receiving no medications at the time of the study.

\section{TRANSOESOPHAGEAL ATRIAL PACING}

A $6 \mathrm{~F}$ quadripolar pacing catheter was passed through the nose and into the oesophagus. The distal or proximal pair of electrodes was used for bipolar pacing and the other pair for monitoring. The initial position was determined as reported by Benson et al. ${ }^{7}$ Final positioning of the electrode was accomplished by electrocardiographic monitoring during electrode adjustment to obtain consistent left atrial capture. Stable capture required $15 \mathrm{~ms}$ pulses of 10 to $22 \mathrm{~mA}$ intensity provided by the pacing device ( $\mathrm{BCO} 2$ and BC02EP, Fukuda Denshi, Tokyo, Japan). After electrode placement, the men rested for at least 10 minutes to stabilise heart rate and blood pressure. Echocardiography was subsequently performed at the resting heart rate and was repeated at each paced rate. Atrial pacing was started at a paced rate of $70 \mathrm{ppm}$. We then increased the rate of atrial pacing by $10 \mathrm{ppm}$ to a maximum of $100 \mathrm{ppm}$. To ensure haemodynamic stabilisation at each paced rate we waited three minutes before the echocardiogram was recorded. A 12 lead electrocardiogram was also recorded at each paced rate.

\section{ECHOCARDIOGRAPHIC STUDY}

Echocardiography was performed with the subject in the supine or left lateral position. A commercial phased array imaging system (SSH 160A, Toshiba, Tokyo, Japan) with pulsed wave and continuous wave Doppler capabilities was used. We used a $2.5 \mathrm{MHz}$ imaging transducer for Doppler echocar- 


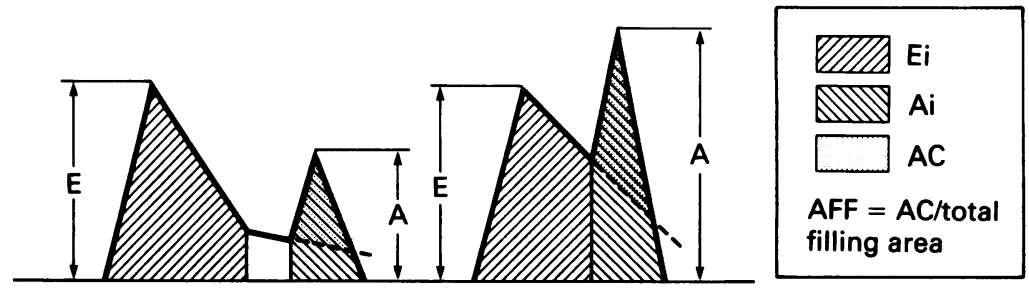

Bradycardia

Tachycardia

Mitral flow measurements

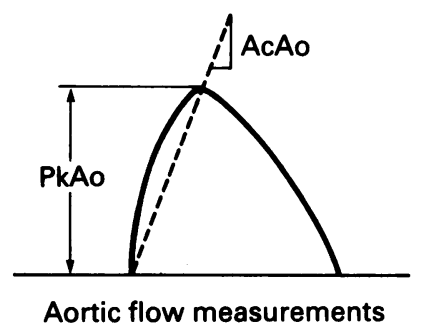

Figure 1 Peak early $(E)$ and late $(A)$ mitral flow velocities and early $(E i)$ and late (Ai) time-velocity integrals were obtained from the mitral flow velocity curve. The atrial filling fraction ( $A F F$ ) was determined as the ratio of the area $(A C)$ above the extrapolated line (broken line) from the passive filling wave to the total filling area. Peak aortic flow velocity $(P k A o)$ and mean aortic flow acceleration (AcAo) were obtained from the aortic flow velocity curve. transducer angulated to record the maximal flow velocity signal in the ascending aorta.

Doppler signals were recorded on a strip chart at a paper speed of $100 \mathrm{~mm} / \mathrm{s}$. The following measurements were obtained from the recordings as shown in fig 1 . The mitral flow velocity curve was characterised by the early filling wave ( $E$ wave) and late filling wave (A wave). The peak flow velocities of an $E$ wave $(E)$ and an $A$ wave (A) were measured and the $E / A$ ratio was calculated. The timevelocity integrals of an $E$ wave (Ei) and an $A$ wave $(\mathrm{Ai})$ were measured as the area under those flow velocity curves and the $\mathrm{Ei} / \mathrm{Ai}$ ratio was also calculated. The atrial filling fraction (AFF) was determined by the method of Kuo et al. ${ }^{8}$ This index was measured as the ratio of the area above the extrapolated line from the passive filling wave (AC) to the total filling area. The peak flow velocity ( $\mathrm{PkAo}$ ) and the mean acceleration from the onset of ejection to PkAo (AcAo) were measured from the aortic flow recording. Each measurement was obtained as a mean value of five consecutive beats to correct for beat to beat variation in the observed values. The mean coefficients of variation of the five observed measurements of the $\mathrm{E}, \mathrm{A}$, and $\mathrm{PkAo}$ at resting sinus rhythm were 5,12 , and $3 \%$, respectively.

diography and a $2.5 \mathrm{MHz}$ non-imaging continuous wave Doppler transducer. Doppler ratio of the variance associated with the lin-
Figure 2 Doppler recording obtained from a representative subject. recordings of mitral flow velocity were performed with the transducer at the cardiac apex. An apical four chamber view of the heart was used to align the Doppler cursor parallel with the apparent flow direction and the sample volume was placed at the level of the mitral annulus. Then the sample volume was moved slightly (with the aid of the audio signal and spectral display) to maximise the signal-tonoise ratio.

Aortic flow velocities were recorded from the suprasternal notch with a non-imaging

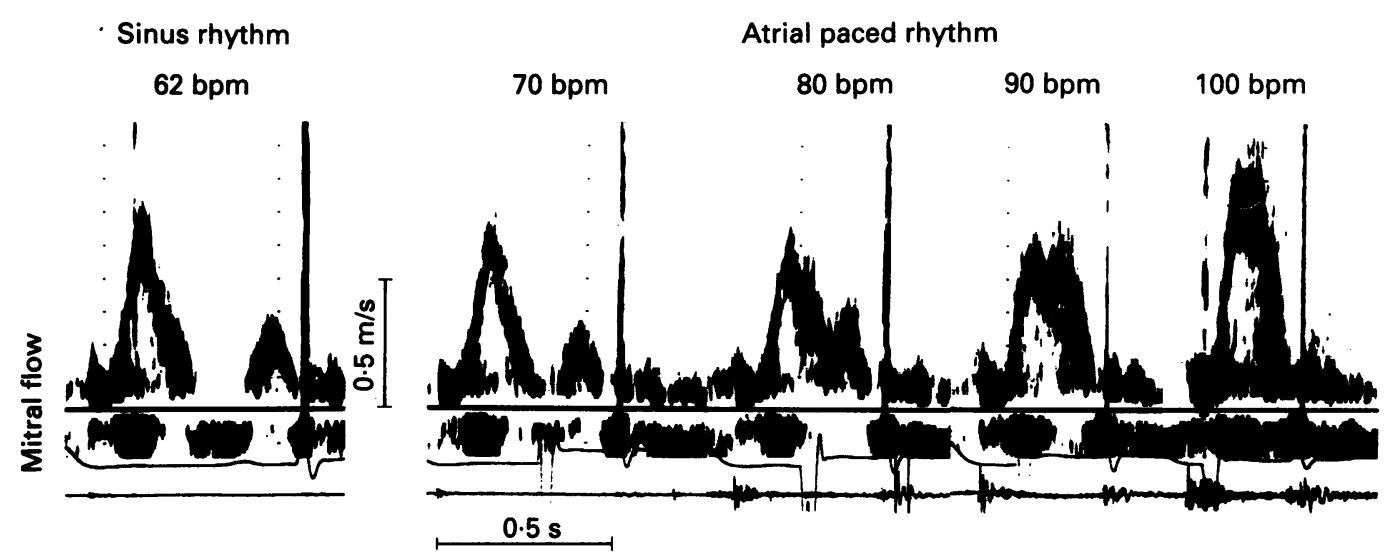

\section{STATISTICAL ANALYSIS}

Values are expressed as mean (SD) in the text and as mean (SEM) in the figures. The relation between the measurements and heart rate was analysed by analysis of variance. We obtained the regression line as well as the coefficient of determination $\left(r^{2}\right)$, which was the earity $\left(S_{L i n}\right)$ to the total variance of the measurement. The ratio of the $S_{\mathrm{Lin}}$ to the variance related to the changes in heart rate $\left(\mathbf{r}^{\prime 2}\right)$ was also obtained as an index of the

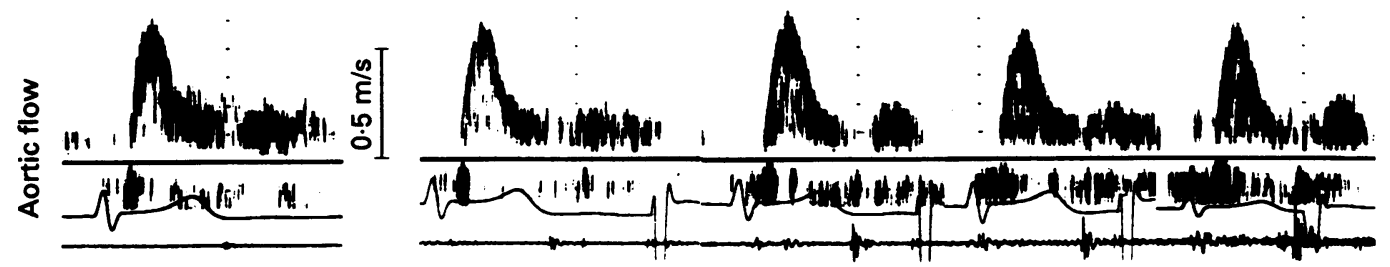


Figure 3 Relation between heart rate and $E / A(A), E$ (circles), and $A$ (squares) ( $B)$. The curvilinear lines indicate the $95 \%$ confidence interval for the regression lines for a particular point. $r^{2}=$ coefficient of determination;

$r^{\prime 2}=$ coefficient of the linearity of the relation between heart rate and the measurement; $S E(\beta)$, standard error of the slope of the regression line.
Figure 4 Relation between heart rate and $\mathrm{Ei} / \mathrm{Ai}(\mathrm{A})$ and $\mathrm{AFF}(\mathrm{B})$. See legend to fig 3 for abbreviations.
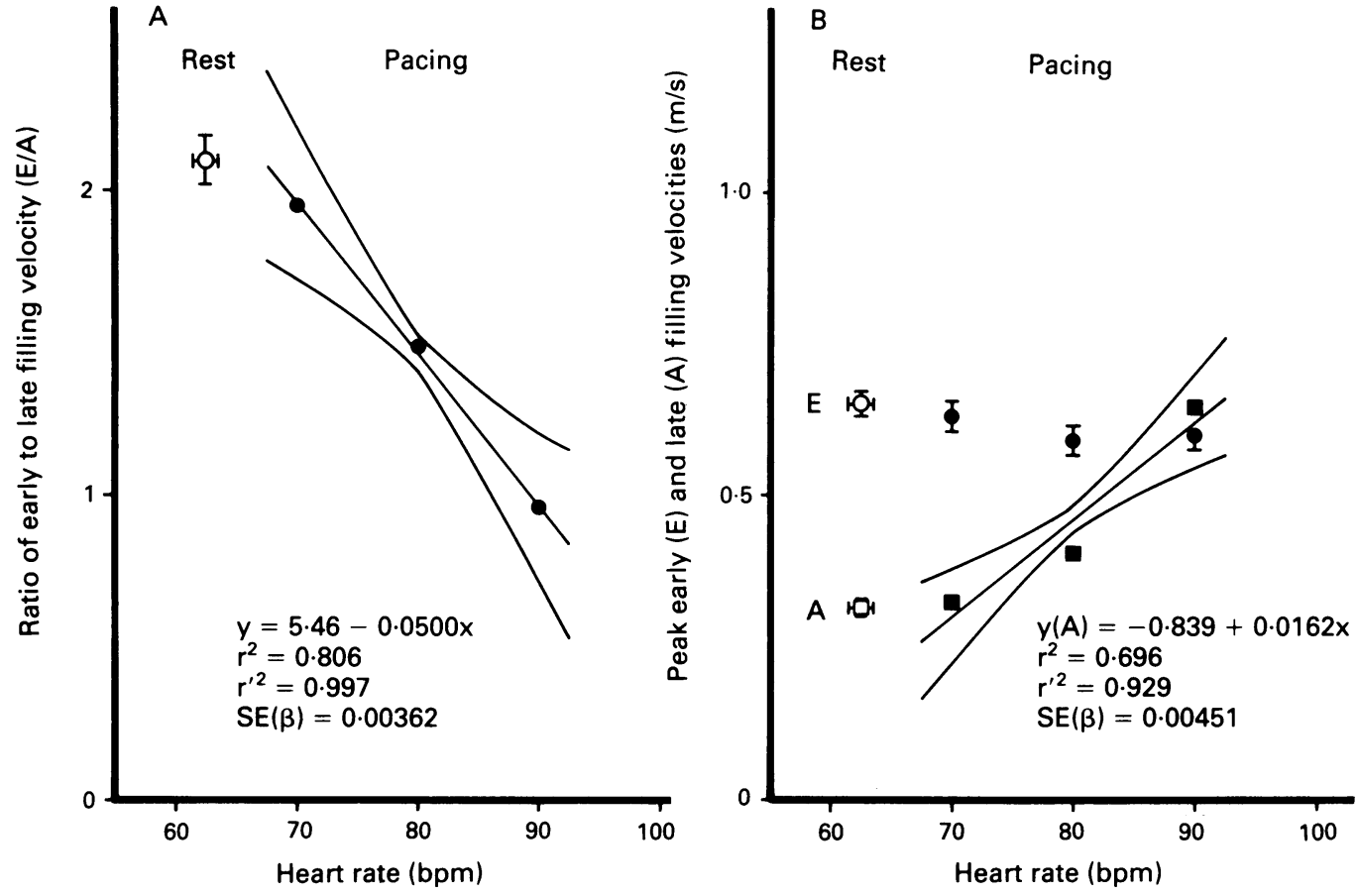

linearity of the relation between the heart rate and the measurement without the influence of other factors, including the intersubject variance and the error. A p value $<0.05$ was regarded as significant.

\section{Results}

Before pacing the mean heart rate was 62.6 (3.3) bpm. The mean resting systolic and diastolic blood pressures were $125 \cdot 3$ (5.7) and $70 \cdot 6(8 \cdot 3) \mathrm{mm} \mathrm{Hg}$. No abnormalities, including ischaemic ST changes, were seen in the 12 lead electrocardiogram during the study.

Figure 2 shows mitral and aortic Doppler recordings from one man. The transmitral flow pattern apparently changed with increasing
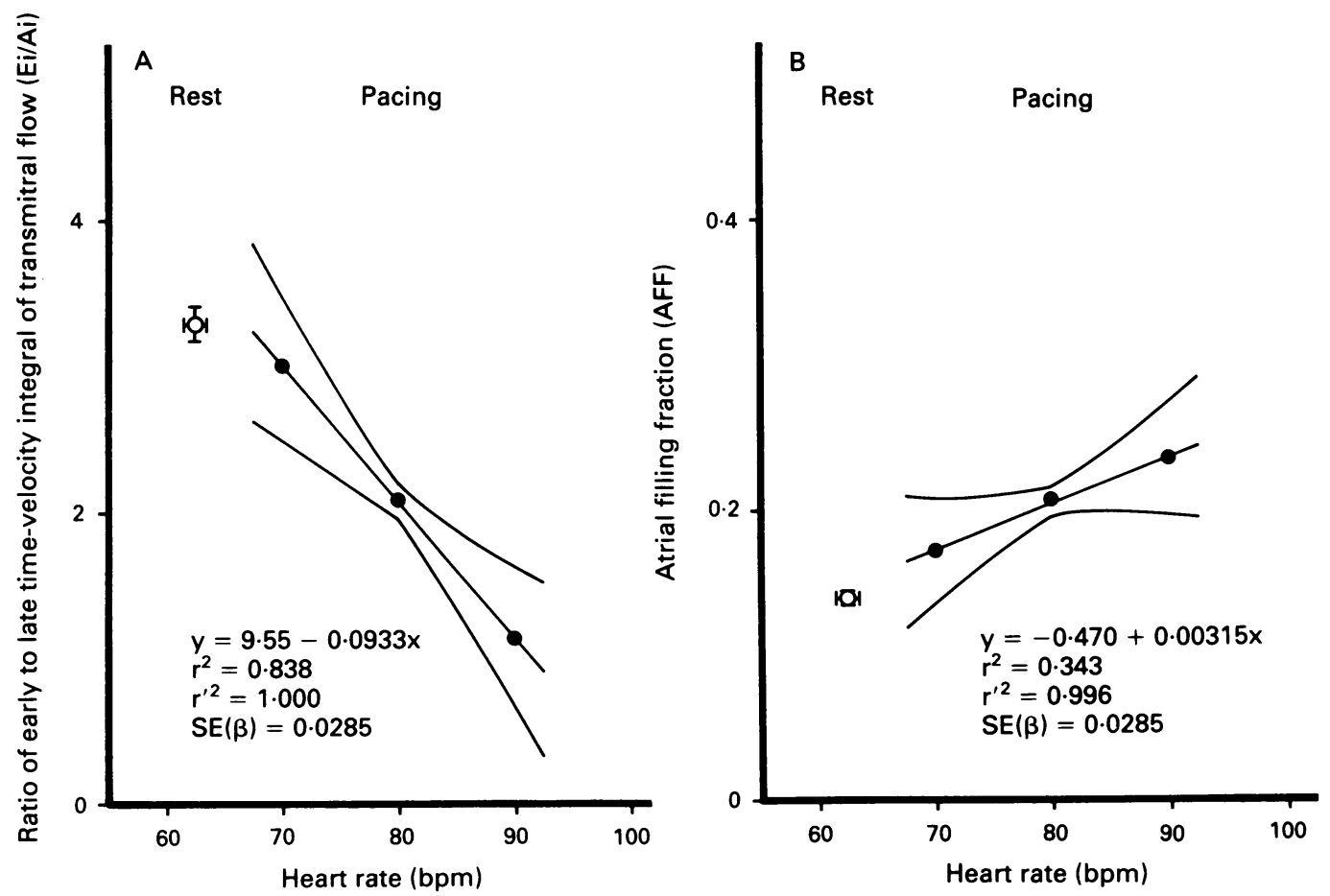

heart rate whereas the aortic flow changed only slightly. Data from all the men were analysed as follows.

EFFECT OF ATRIAL PACING ON MITRAL FLOW An increase in heart rate reduced the $E / A$ ratio (fig 3A). There was an inverse linear relation during pacing $(\mathrm{E} / \mathrm{A}=5.46-0.0500 \times \mathrm{HR}$ $(\mathrm{bpm})\left(\mathrm{r}^{2}=0.806, \mathrm{r}^{\prime 2}=0.997\right)$. Mean values of A during pacing were also significantly affected by a change in heart rate. A was positively correlated with heart rate $(A(\mathrm{~m} / \mathrm{s})$ $=-0.839+0.0162 \times \mathrm{HR}(\mathrm{bpm})\left(\mathrm{r}^{2}=0.696\right.$, $\left.\mathrm{r}^{\prime 2}=0.929\right)$. This relation was somewhat curvilinear. The fact that the variance in the non-linear part of this relation was significant $(p$ 

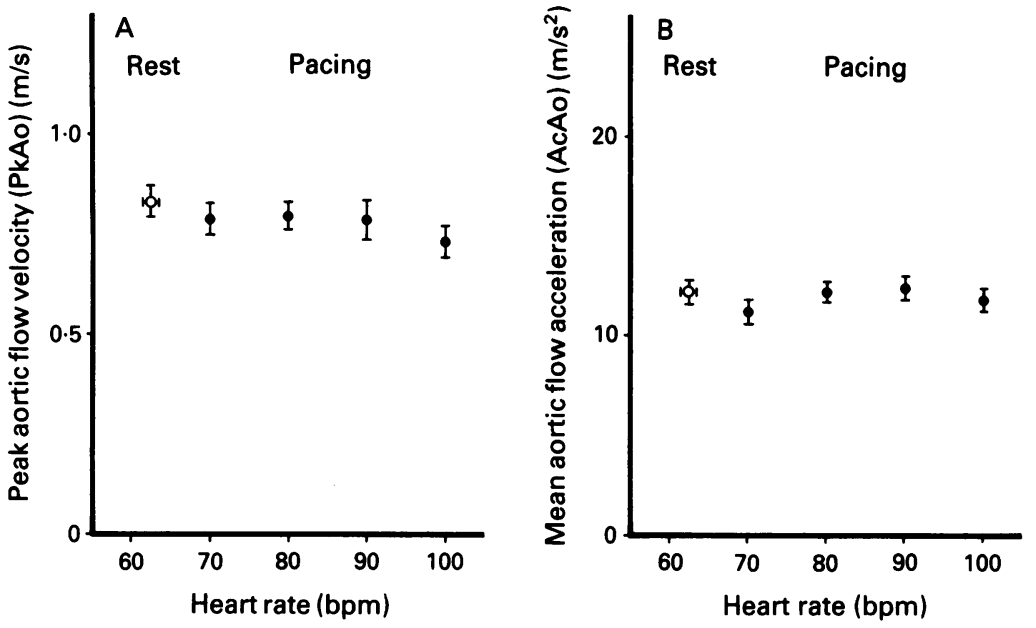

Figure 5 Relation between heart rate and the $\mathrm{PkAo}(A)$ and $A c A o(B)$.

$<0.05)$ compared with the residual variance supported this observation. E, however, did not change significantly with an increase in heart rate (fig 3B). As with the time-velocity integrals, the $\mathrm{Ei} / \mathrm{Ai}$ ratio was negatively correlated $(\mathrm{Ei} / \mathrm{Ai}=9.55-0.0933 \times \mathrm{HR}(\mathrm{bpm})$, $\left.r^{2}=0.838, r^{\prime 2}=1.000\right)$ and AFF was positively correlated $(\mathrm{AFF}=-0.0470+0.00315$ $\left.\times \mathrm{HR}(\mathrm{bpm}), \mathrm{r}^{2}=0.343, \mathrm{r}^{\prime 2}=0.996\right)$ with heart rate (fig 4). The $\mathrm{AC}$ showed no significant change with pacing rate. An increase in the heart rate to $100 \mathrm{ppm}$ during atrial pacing resulted in overlapping of the $A$ and $E$ waves so that the Doppler indices of mitral flow could not be determined.

EFFECT OF ATRIAL PACING ON AORTIC FLOW No significant changes in mean values of $\mathrm{PkAo}$ and AcAo were seen with increasing heart rate (fig 5).

\section{Discussion}

Doppler echocardiography provides blood flow velocity measurements, and various Dopplerderived indices have been used to evaluate cardiac function. ${ }^{910}$ However, Doppler echocardiography cannot be simply applied to individuals because those indices can be influenced by various physiological variables. We found linear relations between heart rate and $\mathrm{E} / \mathrm{A}, \mathrm{Ei} / \mathrm{Ai}$, and $\mathrm{AFF}$ in 10 healthy young men. This provides a basis for correcting the Doppler-derived indices of left ventricular diastolic function.

\section{MITRAL FLOW VELOCITY MEASUREMENTS}

There have been some reports of the effects of heart rate on the diastolic measurements obtained with Doppler echocardiography. Gillam et al reported that an increase in heart rate increased the $A$ and decreased $E, E / A$, and $\mathrm{Ei} / \mathrm{Ai}$ in the patients with pacemakers. ${ }^{11} \mathrm{Herzog}$ et al showed similar results in patients undergoing cardiac catheterisation. ${ }^{12}$ These results suggest that an increase in heart rate may lead to an increase in flow velocity and volume during atrial systole. However, few such studies have been conducted in healthy indi- viduals. Smith et al studied the effects of increased heart rate and blood pressure caused by cold immersion in normal volunteers. ${ }^{13}$ However, the effect of cold immersion can be attributed to the sympathetic nerve stimulation which may change cardiac function as well as heart rate. ${ }^{1415}$ Harrison et al studied the differences between the $E, A$, and $E / A$ at a resting heart rate with sinus rhythm and at a heart rate of $90 \mathrm{bpm}$ during transoesophageal atrial pacing. ${ }^{16}$ They reported that pacing increased $A$ and reduced E/A. Van Dam et al studied the relation between the $E / A$ and resting heart rate and age in healthy volunteers and reported that a higher heart rate was associated with a lower E/A. ${ }^{17}$ As the Doppler indices of diastolic function, including the $\mathrm{E} / \mathrm{A}, \mathrm{Ei} / \mathrm{Ai}$ and $\mathrm{AFF}$ depend on the heart rate, their application to individual subjects requires knowledge of the pattern of their rate dependency. We studied the pattern of the dependency in young healthy men with normal diastolic function.

We found that heart rate correlated closely with E/A and Ei/Ai. Furthermore, because the relation was linear it may be useful in the development of algorithms that will correct for heart rate and enhance the non-invasive assessment of diastolic function in individuals. The pattern of dependency also needs to be studied in individuals with impaired diastolic function.

In addition, the apparent increase in $A$ and in $\mathrm{Ai}$ may be attributed to the effect of the superimposition of the $A$ wave onto the descending limb of the E wave. Pearson et al reported that $P R$ prolongation increased $\mathrm{Ai}$ and that the effect might be caused by superimposition. ${ }^{18}$ We too suggested that superimposition might be important in the effect of heart rate on $\mathrm{Ei} / \mathrm{Ai}^{19}{ }^{19}$ The fact that AFF showed only a weak correlation and AC showed no significant correlation with heart rate in the present study supports this concept.

Our present study had some limitations. There was a small but significant increase in the interval between the pacing artefact and the QRS complex (187 (14), 207 (15), and 217 (19) $\mathrm{ms}$ at paced rates of 70,80 , and $90 \mathrm{ppm}$, respectively). Because an increase in $P R$ interval (as well as an increase in heart rate) causes more superimposition, the effects of changes in heart rate may have been enhanced in the present study.

\section{AORTIC FLOW VELOCITY MEASUREMENTS}

Aortic flow velocity and acceleration are known to reflect the left ventricular systolic function. ${ }^{12}$ Some investigators have studied the effects of heart rate on aortic flow measurements. Wallmeyer et al reported that the peak aortic flow velocity as well as the mean acceleration of aortic flow showed a strong correlation with the $\max \mathrm{dP} / \mathrm{dt}$ and $\max \mathrm{dQ} / \mathrm{dt}$ and was independent of the heart rate in dogs. ${ }^{20}$ On the other hand, Harrison et al in a study of healthy volunteers found an inverse relation between the heart rate and peak aortic flow velocity and acceleration. ${ }^{5}$ They attributed this to a decrease in the end diastolic volume caused by the increased heart rate. We found no relation between aortic flow measurements and heart 
rate. Harrison et al compared the aortic flow measurements at the resting heart rate and at heart rates of from 90 to 150 ppm during atrial pacing, whereas we used paced rates of from 70 to $100 \mathrm{ppm}$. At these low rates a change of heart rate may produce only minimal changes in the Doppler-derived systolic measurements. The relation between heart rate and measurements of aortic flow and mitral flow in health and disease should be further investigated.

We thank Dr A Sakuma, Professor of Clinical Pharmacology Medical Research Institute, Tokyo Medical and Denta University, for his advice on the statistical analysis of the results in this study.

1 Bennett ED, Barclay SA, Davis AL, Mannering D, Mehta N. Ascending aortic blood velocity and acceleration using Doppler ultrasound in the assessment of left ventricula function. Cardiovasc Res 1984;18:632-8.

2 Daley PJ, Sagar KB, Wann LS. Doppler echocardiographic measurement of flow velocity in the ascending aorta during supine and upright exercise. Br Heart J 1985;54:562-7.

3 Rokey R, Kuo LC, Zoghbi WA, Limacher MC, Quinones MA. Determination of parameters of left ventricular diastolic filling with pulsed Doppler echocardiography: comparison with cineangiography. Circulation 1985;71: 543-50.

4 Spirito P, Maron BJ, Bonow RO. Noninvasive assessment of left ventricular diastolic function: comparative analysis of left ventricular diastolic function: comparative analysis of graphic techniques. J Am Coll Cardiol 1986;7:518-26.

5 Harrison MR, Clifton GD, Sublett KL, DeMaria AN. Effect of heart rate on Doppler indexes of systolic function in humans. J Am Coll Cardiol 1989;14:929-35.

6 Plotnick GD. Changes in diastolic function: difficult to measure, harder to interpret. Am Heart $J$ 1989;118: 637-41.

7 Benson DW Jr, Dunnigan A, Benditt DG, Schneider SP. Transesophageal cardiac pacing: history, application, technique. Clin Prog Pacing Electrophysiol 1984;2:360-72.
8 Kuo LC, Quinones MA, Rokey R, Sartori M, Abinader EG, Zoghbi WA. Quantification of atrial contribution to left ventricular filling by pulsed Doppler echocardiography ventricular filling by pulsed Doppler echocardiography
and the effect of age in normal and diseased hearts. $\mathrm{Am} \mathrm{J}$ Cardiol 1987;59:1174-8.

9 Saeian K, Wann LS, Sagar KB. Doppler echocardiographic evaluation of left ventricular function. Echocardiography 990;7:21-5.

10 Labovitz AJ, Pearson AC. Evaluation of left ventricular diastolic function: clinical relevance and recent Doppler echocardiographic insights. Am Heart J 1987;114:836-51.

11 Gillam LD, Homma S, Novick SS, Rediker DE, Eagle KA. The influence of heart rate on Doppler mitral inflow patterns [abstract]. Circulation 1987;76 (suppl IV): 123.

12 Herzog CA, Elsperger KJ, Manoles M, Murakami M, Asinger R. Effect of atrial pacing on left ventricular diastolic filling measured by pulsed Doppler echocardiography [abstract]. J Am Coll Cardiol 1987;9 (suppl A): 197 .

13 Smith SA, Stoner JE, Russel AE, Sheppard JM, Aylward $P E$. Transmitral velocities measured by pulsed Doppler in healthy volunteers: effects of acute changes in blood healthy volunteers: effects of acute changes in

14 Stratton JR, Halter JB, Hallstrom AP, Caldwell JH, Ritchie JL. Comparative plasma catecholamine and hemodynamic responses to handgrip, cold pressor and supine bicycle exercise testing in normal subjects. J Am Coll Cardiol 1983;2:93-104

15 Walsh RA. Sympathetic control of diastolic function in congestive heart failure. Circulation 1990;82 (suppl I): 52-8.

16 Harrison MR, Clifton GD, Berk MR, Smith MD, DeMaria AN. Effect of heart rate on Doppler indices of left ventricular diastolic filling in man [abstract]. $J \mathrm{Am}$ Coll Cardiol 1990;15 (suppl A): 164

17 Van Dam I, Fast J, De Boo T, et al. Normal diastolic filling patterns of the left ventricle. Eur Heart J 1988;9:165-71.

18 Pearson AC, Janosik DL, Redd RR, Buckingham TA, Blum RI, Labovitz AJ. Doppler echocardiographic assessment of the effect of varying atrioventricular delay and pacemaker mode on left ventricular filling. Am Heart $J$ pacemaker mode

19 Oniki T, Hashimoto Y, Shimizu S, et al. Effect of changes in heart rate and atrioventricular delay on left ventricular heart rate and atrioventricular delay on left

20 Wallmeyer K, Wann LS, Sagar KB, Kalbfleisch J, Klopfenstein HS. The influence of preload and heart rate on Doppler echocardiographic indexes of left ventricular performance: comparison with invasive indexes in an experimental preparation. Circulation 1986;74:181-6. 